\title{
Disentangling the causes of maturation trends in exploited fish populations
}

\section{Idea and coordination: C. Tara Marshall, Howard I. Browman}

\section{CONTENTS}

Marshall CT, Browman HI

Introduction

$249-251$

Dieckmann U, Heino M

Probabilistic maturation reaction norms: their history, strengths, and limitations

Law $\mathbf{R}$

Fisheries-induced evolution: present status and future directions

\section{Wright PJ}

Understanding the maturation process for field investigations of fisheries-induced evolution
Thorpe JE

Maturation responses of salmonids to changing

developmental opportunities $285-288$

Morita K, Fukuwaka M

Why age and size at maturity have changed in

Pacific salmon $289-294$

\section{Kraak SBM}

Does the probabilistic maturation reaction norm approach disentangle phenotypic plasticity from genetic change?

\section{Marshall CT, McAdam BJ}

Integrated perspectives on genetic and environmental effects on maturation can reduce

potential for errors of inference $301-310$

\section{Introduction}

\author{
C. Tara Marshall ${ }^{1, *}$, Howard I. Browman ${ }^{2}$ \\ ${ }^{1}$ School of Biological Sciences, University of Aberdeen, Tillydrone Avenue, Aberdeen AB24 2TZ, UK \\ ${ }^{2}$ Institute of Marine Research, Austevoll Research Station, 5392 Storebø, Norway
}

Evolutionary theory predicts that selective harvesting will shift the frequency of genes for heritable traits towards those that express well-adapted phenotypes (Law 2007, this Theme Section). Applying this logic, commercial fisheries that select on the basis of size could reasonably be expected to favor the genotype for maturation at smaller sizes (and/or younger ages), given that rapidly maturing individuals will be more likely to reproduce prior to capture. This form of fisheries-induced evolutionary response is a parsimonious explanation for the observed longterm trend towards earlier maturation that has been observed in several commercially exploited fish stocks (Rijnsdorp 1993, Trippel 1995). Unfortunately, it is not possible to test this hypothesis directly, be- cause the genes associated with maturation have not been isolated.

Probabilistic maturation reaction norms (PMRNs) (Heino et al. 2002) have been proposed as a statistical tool for helping to disentangle genetic from plastic effects on maturation (reviewed by Dieckmann \& Heino 2007, this Theme Section). For a given cohort, the PMRN describes the maturation probability of individuals that have survived to reach a given age and size. A midpoint curve, illustrating the age and size at which the maturation probability is $50 \%$, is often used to summarise the PMRN. A shift in cohort-specific PMRNs over time is interpreted as being consistent with (although not direct evidence of) a genetic change at the population level. For example, a shift through 
time and across cohorts towards midpoints located at smaller sizes and younger ages agrees with the expected life history response to high rates of selective exploitation.

On the basis of directional shifts in PMRNs fit to historical data, a number of studies have concluded that fisheries-induced evolution in maturation rates has occurred (see Dieckmann \& Heino 2007). For example, PMRNs were used to infer that a fisheries-induced evolutionary response in the maturation rates of the Northern cod stock was rapid and preceded stock collapse (Olsen et al. 2004). Fisheries-induced changes to the genetic structure of a population alter the genetic diversity in life-history traits (Conover \& Munch 2002, Kenchington et al. 2003). Such structural changes to the population are regarded as rapidly induced, but slow to reverse (Law \& Grey 1989, Barot et al. 2004). Further, since the individual growth rate of many fishes slows following maturation, a decrease in the size at which individuals mature could result in reduced yields (Law \& Grey 1989). For these reasons, fisheries managers are increasingly being challenged to adopt so-called Darwinian fisheries approaches to management (Conover 2000, Kenchington et al. 2003, Conover et al. 2005).

Despite the intuitive appeal of fisheries-induced evolution, the PMRN-based evidence is unavoidably circumstantial, due to the lack of unambiguous genetic evidence. Further, the majority of PMRNs published to date employ observations from fisheries databases to estimate the probability of a given cohort becoming mature as a function of age and length. While these databases are potentially long enough to detect evolutionary responses, they contain information on a limited suite of biological variables (typically age, length, weight, sex and stage of maturation) measured at discrete times. These databases do not contain information which would allow the sequence of hormonal and morphological changes that precede maturation (see Thorpe 2007, Wright 2007; both in this Theme Section) to be resolved in detail. Inferences made using the PMRN approach are therefore based on the assumption that age and length at the point at which individuals become mature accurately reflect the physiological status of immature individuals at discrete time points when they are 'deciding' whether to proceed with, or delay, maturation. These developmental decisions are influenced by environmental conditions (Aubin-Horth et al. 2006) and by the magnitude of stored energy reserves in relation to anticipated energy expenditures (Thorpe et al. 1998). The assumption that age and length at the point of maturation are an accurate representation of the physiological processes that have occurred throughout the immature stage is difficult to test for wild stocks, although rate-based PMRNs have been developed for organisms studied in captivity (Van Dooren et al. 2005). If this assumption is invalid, then it is possible that the environmental effects on decisions regarding maturation have not been accurately controlled for by PMRNs.

The goal of this Theme Section is to present some of the latest information on physiological processes leading to maturation in fishes and to assess the strengths and weaknesses of the PMRN approach in light of this information. Contributions were sought from individuals with experience in experimental and/or field research in fish growth and maturation, as well as experts in evolutionary aspects of maturation. Their remit was to discuss questions such as

- Is the PMRN approach suitable for diagnosing genetic changes in maturation rates, and if not, what method would be suitable?

- Is the current evidence for fisheries-induced evolution conclusive, and if not, why not?

- Is there contradictory evidence?

- Have environmental effects on maturation been adequately accounted for?

- Can the physiological basis for maturation be captured by maturation reaction norms?

- How can maturation reaction norms be made more realistic?

- What type of studies would enhance our understanding of genotypic control of maturation?

The preceding questions indicate that the Theme Section was initially conceived as an outlet for viewpoints other than those of proponents of the PMRN approach - we felt that the viewpoint of the latter group was well-represented by a number of recent publications. Once the roster of contributors was confirmed, Ulf Dieckmann and Mikko Heino - the preeminent developers of the PMRN approach to fisheries data - were informed of the Theme Section and provided with a list of contributors and titles. They were invited to contribute and generously agreed to prepare a historical review that summarized their own perspective. We are most grateful to Ulf and Mikko for accepting our invitation, and for providing such a thorough and scholarly article. It will do much to clarify understanding of the PMRN approach.

Although a minority of authors exchanged drafts of their manuscripts, this was not coordinated. Therefore, the Theme Section should not be viewed as an interactive debate on the PMRN approach. The Theme Section was not confined entirely to the PMRN approach: the contribution by Law (2007) highlights the importance of having older age-classes in the population. When read together, the contributions to this Theme Section will surely impress upon readers that disentangling the multiple causes of maturation trends in 
fish populations is an inherently complex task. Consequently, it is not surprising to find a range of perspectives on what factors are of principal importance. Nonetheless, there was a degree of convergent thinking amongst the contributors regarding the proximate cues for maturation that are of critical importance. Criticisms of the PMRN approach to analyzing maturation trends centered on the possibility that proximate cues for maturation were not adequately accounted for. The contribution by Dieckmann \& Heino (2007) is distinctive in that it does not cover the physiology of maturation, but instead concentrates on a wide range of evolutionary and ecological effects on maturation. Their contribution makes clear that the PMRN approach to analyzing trends in maturation arose from a consideration of the ultimate causes of maturation, rather than proximate cues. These 2 contrasting viewpoints can be considered as yet another variant of the debate over the relative importance of bottom-up (environment impacting maturation through physiological effects) and top-down (fisheries as selective predation impacting maturation through genetic effects) regulation of life histories. Reconciling the 2 viewpoints, such that inter- and intra-annual variation in the physiological status of immature individuals is eliminated as a potentially confounding element in the reaction norm analysis, would strengthen conclusions regarding both the time-scale and magnitude of the fisheries-induced evolutionary response in maturation rates.

There are several encouraging signs that the large gap between studies investigating proximate and ultimate sources of variation in maturation rates is being bridged. For example, 3-dimensional PMRNs have been developed to account for the effect that condition (as represented by a morphometric index) has on maturation of North Sea plaice (Grift et al. 2007). Morita \& Fukuwaka (2007, this Theme Section), Kraak (2007, this Theme Section) and Marshall \& McAdam (2007, this Theme Section) fit PMRNs to data, indicating the willingness of biologists to evaluate the strengths and weaknesses of PMRNs from a critical but open-minded viewpoint. These recent studies demonstrate that a combination of approaches, integrating biology, physiology and ecology with analytical techniques and theory, will be required to disentangle the sources of variation in the maturation rates of exploited fish populations.

Acknowledgements. We thank the contributors for their patient and timely efforts to comply with our editorial suggestions. We thank U. Dieckmann and M. Heino for comments on an earlier draft. H.I.B.'s research, and his editorial activity, are supported by the Institute of Marine Research, Norway, the Research Council of Norway, and the Inter-Research Science Center.

\section{LITERATURE CITED}

Aubin-Horth N, Bourque JF, Daigle G, Hedger R, Dodson JJ (2006) Longitudinal gradients in threshold sizes for alternative male life history tactics in a population of Atlantic salmon (Salmo salar). Can J Fish Aquat Sci 63:2067-2075

Barot S, Heino M, O'Brien L, Dieckmann U (2004) Long-term trend in the maturation reaction norm of two cod stocks. Ecol Appl 14:1257-1271

Conover DO (2000) Darwinian fishery science. Mar Ecol Prog Ser 208:303-307

Conover DO, Munch SB (2002) Sustaining fisheries yields over evolutionary time scales. Science 297:94-96

Conover DO, Arnott SA, Walsh MR, Munch SB (2005) Darwinian fishery science: lessons from the Atlantic silverside (Menidia menidia). Can J Fish Aquat Sci 62:730-737

Dieckmann U, Heino M (2007) Probabilistic maturation reaction norms: their history, strengths, and limitations. Mar Ecol Prog Ser 335:253-269

Grift RE, Heino M, Rijnsdorp AD, Kraak SBM, Dieckmann U (2007) Three-dimensional maturation reaction norms for North Sea plaice. Mar Ecol Prog Ser 334:213-224

Heino M, Dieckmann U, Godo OR (2002) Estimating reaction norms for age and size at maturation with reconstructed immature size distributions: a new technique illustrated by application to Northeast Arctic cod. ICES J Mar Sci 59:562-575

Kenchington E, Heino M, Nielsen EE (2003) Managing marine genetic diversity: time for action? ICES J Mar Sci 60: 1172-1176

Kraak SBM (2007) Does the probabilistic maturation reaction norm approach disentangle phenotypic plasticity from genetic change? Mar Ecol Prog Ser 335:295-300

Law R (2007) Fisheries induced evolution: present status and future directions. Mar Ecol Prog Ser 335:271-277

Law R, Grey DR (1989) Evolution of yields from populations with age-specific cropping. Evol Ecol 3:343-359

Marshall CT, McAdam BJ (2007) Integrated perspectives on genetic and environmental effects on maturation can reduce the potential for errors of inference. Mar Ecol Prog Ser 335:301-310

Morita K, Fukuwaka M (2007) Why age and size at maturity have changed in Pacific salmon. Mar Ecol Prog Ser 335:289-294

Olsen EM, Heino M, Lilly GR, Morgan MJ, Brattey J, Ernande B, Dieckmann U (2004) Maturation trends indicative of rapid evolution preceded the collapse of northern cod. Nature 428:932-935

Rijnsdorp AD (1993) Selection differentials of male and female North Sea plaice and changes in maturation and fecundity. In: Stokes TK, McGlade JM, Law R (eds) The exploitation of evolving resources. Springer-Verlag, Berlin, p 19-36

Thorpe JE (2007) Maturation responses of salmonids to changing developmental opportunities. Mar Ecol Prog Ser 335:285-288

Thorpe JE, Mangel M, Metcalfe NB, Huntingford FA (1998) Modelling the proximate basis of salmonid life-history variation, with application to Atlantic salmon, Salmo salar L. Evol Ecol 12:581-599

Trippel EA (1995) Age at maturity as a stress indicator in fisheries. BioScience 45:759-771

Van Dooren TJM, Tully T, Ferrière R (2005) The analysis of reaction norms for age and size at maturity using maturation rate models. Evolution 59:500-506

Wright PJ (2007) Understanding the maturation process for field investigations of fisheries-induced evolution. Mar Ecol Prog Ser 335:279-283 